\title{
Xenofobia e violência de gênero: uma análise de manchetes veiculadas no webjornalismo brasileiro sobre mulheres venezuelanas
}

- Xenofobia y violencia de género: un análisis de los titulares de las mujeres venezolanas en el periodismo web brasileño

- Xenophobia and gender violence: an analysis of headings broadcasted in brazilian webjornalism on venezuelan women

Mauro Machado do Prado'

Ana Paula de Castro Neves ${ }^{2}$

Nathália Machado Cardoso Dardeau de Albuquerque

Resumo: O presente trabalho consiste em um estudo qualitativo das representações sociais de imigrantes venezuelanas na América do Sul no período de 2016 a 2019, a partir de manchetes de notícias divulgadas em jornais digitais brasileiros. O objetivo é verificar a ocorrência ou não de veiculações que constituam de forma explícita ou implícita uma violação à dignidade e

1 Professor da Universidade Federal de Goiás. É docente do Programa de Pós-Graduação Interdisciplinar em Direitos Humanos - Mestrado e Doutorado da UFG. mauromachadodoprado@gmail.com

2 Possui gradução em Direito (UFG). Doutoranda e Mestre do Programa de Programa de Pós-Graduação Interdisciplinar em Direitos Humanos - (PPGIDH) da UFG. Graduada em Direito. anapaula_castro@discente.ufg.br

3 Possui graduação em Direito. Mestranda em Direitos Humanos do Programa de Programa de Pós-Graduação Interdisciplinar em Direitos Humanos - (PPGIDH) da UFG. nathaliadardeau@gmail.com 
aos direitos dessas mulheres, ao fomentar ou incitar a xenofobia e a violência de gênero na sociedade através de palavras, frases ou expressões capazes de provocar um aniquilamento simbólico. Para tanto, realizou-se um estudo bibliográfico e documental acerca das vulnerabilidades sociais presentes nos processos imigratórios contemporâneos, que foi consubstanciado com a análise de conteúdo (BARDIN, 2009), em abordagem qualitativa, de manchetes publicadas em jornais digitais brasileiros. A partir da análise realizada, foi possível inferir que estes veículos de comunicação vêm frequentemente descrevendo a migração venezuelana como um problema, mas em conotação negativa, sem o cuidado de descrição do contexto de forma mais clara e abrangente da questão a ser noticiada.

Palavras-chave: Direitos humanos das mulheres. Violência de gênero. Xenofobia. Webjornalismo.

Resumen: El presente trabajo consiste en un estudio cualitativo de las representaciones sociales de los inmigrantes venezolanos en América del Sur en el período de 2016 a 2019, a partir de titulares de noticias publicados en periódicos digitales brasileños. El objetivo es verificar la ocurrencia o no de colocaciones que constituyan explícita o implícitamente una violación a la dignidad y derechos de estas mujeres, al promover o incitar la xenofobia y la violencia de género en la sociedad a través de palabras, frases o expresiones capaces de provocar una aniquilación simbólica. Para ello, se realizó un estudio bibliográfico y documental sobre las vulnerabilidades sociales presentes en los procesos migratorios contemporáneos, el cual fue fundamentado con análisis de contenido (BARDIN, 2009), en un enfoque cualitativo, de titulares publicados en diarios digitales brasileños. Del análisis realizado, se pudo inferir que estos medios de comunicación han venido describiendo muchas veces la migración venezolana como un problema, pero en una connotación negativa, sin preocuparse por describir de manera más clara y completa el contexto del tema a reportar.

Palabras clave: Derechos humanos de la mujer. La violencia de género. Xenofobia. Periodismo web.

Abstract: The present work consists of a qualitative study of the social representations of Venezuelan immigrants in South America in the period from 2016 to 2019, based on news headlines published in Brazilian digital news- 
papers. The objective is to verify the occurrence or not of placements that explicitly or implicitly constitute a violation of the dignity and rights of these women, by promoting or inciting xenophobia and gender violence in society through words, phrases or expressions capable of provoking a symbolic annihilation. To this end, a bibliographic and documentary study was carried out on the social vulnerabilities present in contemporary immigration processes, which was substantiated with content analysis (BARDIN, 2009), in a qualitative approach, of headlines published in Brazilian digital newspapers. From the analysis carried out, it was possible to infer that these media outlets have often been describing Venezuelan migration as a problem, but in a negative connotation, without taking care to describe the context more clearly and comprehensively of the issue to be reported.

Keywords: Women's human rights. Gender-based violence. Xenophobia. Webjournalism.

\section{Introdução}

A história dos processos migratórios internacionais no Brasil remonta ao período colonial e revela tratamentos diferenciados ora explícitos e regulamentados, ora implícitos, com distinções no acolhimento por parte da sociedade e do Estado brasileiro, inclusive no que se refere à concessão de direitos civis, políticos e sociais aos imigrantes. Infere-se da realidade apontada pela literatura especializada que estas distinções na aceitação e na tutela dos imigrantes são identificáveis ainda e mais acirradamente nos dias de hoje, não tanto pelo aumento do fluxo destes movimentos nos últimos anos - já que foi igualmente significativo em outros momentos da história - mas pelo fato de que as migrações internacionais constituem, atualmente, um fenômeno global experimentado por quase todas as nações (WIHTOL DE WENDEN, 2013).

De acordo com o Relatório Anual do Observatório das Migrações Internacionais (OBMigra), lançado pelo Ministério da Justiça em 2019, o Brasil registrou, de 2010 a 2018, um total de 774,2 mil imigrantes e refugiados, dentre os quais um número expressivo advém da Venezuela, que vive hoje uma crise humanitária (BRASIL, 2019), considerada pela Agência da ONU para Refugiados no Brasil (ACNUR) como a segunda maior do mundo, ficando atrás apenas daquela vivida na Síria (ACNUR, 2019).

Outros dados que merecem destaque são os recém-publicados pela Operação Acolhida, uma força-tarefa criada em 2018 pelo Governo Federal 
e promovida pelo Exército Brasileiro com o apoio de agências da ONU e de mais de 100 entidades da sociedade civil, que apontam que, até junho de 2020, foram realizados 889.859 atendimentos na fronteira do Brasil com a Venezuela, sendo que 264.865 venezuelanos solicitaram regularização migratória e 129.558 solicitaram residência no país. A Operação levantou ainda a realização de 216.738 atendimentos sociais, a emissão de 251.670 cadastros de pessoas físicas (CPFs) e de 89.173 carteiras de trabalhos a migrantes venezuelanos (BRASIL, 2020).

Diante do aumento do fluxo migratório experimentado pelo Brasil nos últimos anos e dos reflexos dele decorrentes, foi promulgada a Lei $n^{\circ}$ $13.445 / 2017$, que dispõe sobre os direitos e os deveres do migrante e do visitante, regula a sua entrada no país e estabelece princípios e diretrizes para as políticas públicas para o emigrante (BRASIL, 2017). Ressalta-se ainda que mais recentemente, em 2019 foi criada pela Câmara dos Deputados uma comissão externa destinada a tratar da crise na Venezuela, em especial na fronteira com o Brasil, com o intuito de "subsidiar o Governo Federal com informações para solucionar os problemas na fronteira com o Brasil e da Venezuela causados pela crise que esse país enfrenta e viu agravada nos últimos dias" (BRASIL, 2019).

No contexto de aversão ao indivíduo por sua condição de estrangeiro, nota-se a existência de um grupo específico de imigrantes que não raramente é ignorado pelos Estados e pela sociedade como um todo: as mulheres e meninas, consideradas pela Agência da ONU para Refugiados no Brasil - ACNUR como sendo as mais afetadas nos processos migratórios, pontuando a pobreza, a separação da família, as dificuldades no acesso a serviços básicos e exposição a maiores riscos de violência como algumas das principais dificuldades enfrentadas (ACNUR, 2019).

Diante dessa triste realidade, o presente estudo partiu da premissa de que um número considerável de matérias publicadas pelo webjornalismo ${ }^{4}$ brasileiro poderiam constituir elas mesmas - de forma velada ou não - uma violação dos direitos de mulheres venezuelanas que residem atualmente no Brasil. Isso porque defendemos que a frequente associação dessas mulheres à pobreza, prostituição e mendicância, pode resultar em um perigoso meio de fomento à discriminação e à intolerância.

Frente ao exposto, este artigo é resultado da análise de conteúdo em uma abordagem qualitativa de dez manchetes ${ }^{5}$ constantes de notícias rela-

4 O webjornalismo, jornalismo online, ciberjornalismo, jornalismo eletrônico ou jornalismo digital é o jornalismo dos meios digitais, como CD-ROM e internet

5 "Título principal, composto em letras garrafais e publicado com grande destaque, geralmente no alto da primeira página de um jornal ou revista. Indica o fato jornalístico de maior importância entre as notícias contidas na edição" (BARBOSA; RABAÇA, 1995, p. 379). 
cionadas a migrantes venezuelanas, veiculadas em três importantes jornais digitais (Folha de São Paulo, Estadão e VICE Brasil) no período de 2016 a 2019. Ressalta-se que a busca por estas manchetes foi realizada através de sítios de pesquisa, utilizando-se os descritores migrantes/mulheres/venezuelanas e que foram selecionadas as consideradas mais atentatórias aos direitos dessas mulheres, o que igualmente permitiu delimitar as categorias e unidades de registros da presente pesquisa.

Desse modo, tem-se uma proposta interdisciplinar de análise e reflexão de narrativas veiculadas em manchetes de importantes jornais digitais que constituem, por si só, uma violação aos direitos de migrantes venezuelanas que optaram por fixar residência no território brasileiro. A elaboração se justifica pela necessidade de se compreender como tem sido a realidade dessas mulheres no país e como a mídia - mais especificadamente o webjornalismo - é capaz de influenciar a opinião pública e os indivíduos de forma negativa quando os estigmatizam.

Esclarece-se que o objetivo deste trabalho não é o de conceituar ou diferenciar termos específicos relacionados aos processos migratórios, motivo pelo qual optou-se pela utilização dos termos "migrantes" e "imigrantes" para fazer referência aos indivíduos que se deslocam de um país para outro com o objetivo de ali se estabelecer, incluindo-se os refugiados. Isso porque, assim como Ventura (2020), acreditamos que - mais do que conceitos e definições - as migrações internacionais têm demandado análise crítica dos contextos em que emergem os deslocamentos humanos, das dinâmicas, das tensões, condições e repercussões para os indivíduos envolvidos.

\section{Xenofobia e violência de gênero}

Uma das maiores preocupações relacionadas aos processos migratórios internacionais contemporâneos é a xenofobia. Nota-se que, com o aumento do número de imigrantes pelo mundo, cresceu também a violência por esses sofrida e que é constantemente retratada pela mídia. Para a Organização Internacional para as Migrações (OIM), a xenofobia pode ser descrita como "atitude, preconceito ou comportamento que rejeita, exclui e, frequentemente, diminui pessoas com base na percepção de que são estranhas ou estrangeiras relativamente à comunidade, à sociedade ou à identidade nacional" (OIM, 2009, p. 80).

Ressalta-se que a aversão aos estrangeiros pelo mundo tem sido tão recorrente que, em junho do ano em curso, o Conselho dos Direitos Humanos 
da ONU fez um apelo ${ }^{6}$ durante uma reunião em Genebra quanto à necessidade de se discutir e de se combater a discriminação racial pelo mundo, diante do aumento de incitações à violência, ao discurso de ódio e de ideologias nacionais violentas fundadas em prejulgamentos raciais.

Fato é que, além da xenofobia, nota-se a existência de uma parcela de pessoas que vêm sofrendo uma segunda estigmatização dentro dos processos migratórios internacionais: as mulheres. Observa-se, assim, uma dupla estigmatização das mulheres imigrantes, que, além de estarem sujeitas a violações em razão da condição de estrangeira, estão ainda sujeitas a violações em razão do gênero feminino.

Sabe-se que a violência contra mulheres é fruto das desigualdades sócio históricas entre os gêneros e tem seus fundamentos nas relações desiguais de poder entre homens e mulheres (SCOTT, 1995). Aliás, diversos estudos apontam que os valores machistas e patriarcais ainda estão presentes no mundo de hoje, importando em violações graves e recorrentes contra mulheres que ainda estão submetidas a sérias desigualdades de poder e de direitos em nossa sociedade (CHAUÍ, 2003; DINIZ; ANGELIM, 2003; MACHADO, 2000; SAFFIOTI, 1999).

Segundo Saffioti (2011), seja qual for a forma de violência praticada contra as mulheres, a moral e a emocional estão sempre presentes. Para a autora, as construções sociais relacionadas ao gênero colocam as mulheres em uma posição de submissão 7 aos homens que são, a partir daí, considerados dominadores, detentores do poder. Safiotti assevera ainda que as manifestações violentas surgem, sobretudo, como forma de destruição ou ataque da subjetividade do outro quando o sujeito sente que está perdendo o seu poder ou quando se depara com um sentimento de impotência (SAFFIOTI, 1999).

Neste sentindo, a violência contra mulheres revela as marcas da opressão existentes no contexto da diferença de gênero, refletindo, assim, os fatores históricos e culturais de uma sociedade. As mulheres acabam, pelas diferenças biológicas, sendo vistas e representadas como pessoas dominadas e submissas, o que acaba provocando uma coisificação ${ }^{8}$ dessas mulheres, suprimindo sua condição de sujeito de direitos, anulando e impedindo suas atividades e sua fala (CHAUÍ, 1985).

6 ONU. AuConseildesdroits de l'homme de l'ONU, appelaudémantèlement de structures d’oppressionraciale. 16 jun. 2020. Disponível em: https://www.ungeneva.org/fr/node/60199. Acesso em: 20 jul. 2020.

7 As identidades sociais se constroem, sobretudo, no plano inconsciente, podendo ser pequena ou grande sua presença no nível consciente. Isto em nada diminui a importância política destas realidades, uma vez que as atividades humanas são levadas a cabo, na produção e na reprodução da vida, por portadores de inconsciente e de consciência (SAFFIOTI, 2004, p. 67).

8 Todo ato de brutalidade, sevícia e abuso físico e/ou psíquico contra alguém caracteriza relações intersubjetivas e sociais definidas pela opressão, intimidação, pelo medo ou terror (CHAUI, 2011, p. 342). 
É certo que muitas Nações já reconhecem hoje a importância e a necessidade de se criar meios que tutelem a proteção dos Direitos Humanos das Mulheres. Contudo, apesar dos esforços realizados não só pelos Estados como também por organismos internacionais, nota-se que os instrumentos e as práticas desenvolvidas têm se mostrado ineficazes no combate à violência de gênero, fato este que pode ser comprovado pelas altas taxas de violência contra as mulheres em vários lugares do mundo, frequentemente reportadas pela mídia e identificadas por estudos específicos.

Ocorre que, ao veicularem notícias que tenham os migrantes internacionais como objeto, muitos autores utilizam termos, expressões e afirmações que acabam estigmatizando, diminuindo ou ainda menosprezando esses indivíduos, principalmente quando os associam à pobreza, violência, marginalização, prostituição ou lhes atribuem características negativas. Verifica-se que essas violações são ainda mais evidentes quando as notícias se reportam às mulheres imigrantes, o que favorece não apenas a xenofobia como também a desigualdade de gênero.

Destarte, narrativas xenófobas veiculadas pela mídia - mesmo que de forma implícita e involuntária - podem ser ainda mais atentatórias quando associadas ao gênero feminino, uma vez que revelam e incitam não somente a aversão ao estrangeiro, como também as marcas da opressão a que as muIheres ainda são submetidas, baseadas na sua condição de gênero, refletindo fatores históricos e culturais (negativos) de um dado grupo social.

\section{O poder simbólico da mídia}

Ao analisar a influência das mídias em um contexto de gênero, Thompson (2001) evidencia a relevância do conteúdo e das narrativas constantes nas notícias que são difundidas, tendo em vista que podem construir um senso comum capaz de favorecer ainda mais a desigualdade.

De igual modo, Guacira Louro (2018) aponta que as diferenças que hierarquizam sujeitos estão constantemente sendo produzidas nos meios sociais através de processos linguísticos e discursivos, num campo político, uma vez que nele estão implicadas as relações de poder. Ainda segundo a autora, a linguagem institui e demarca os lugares dos gêneros não apenas pelo ocultamento do feminino, mas também ao favorecer a superioridade de um gênero sobre outro, representando, assim, uma intervenção no curso dos acontecimentos, de modo a influenciar as ações dos outros e produzir eventos por meio da produção e transmissão de formas simbólicas (THOMPSON, 2001).

Infere-se, portanto, que as notícias divulgadas em jornais e outros meios de comunicação podem conter narrativas que acabem inferiorizando as muIheres ou tornando-as invisíveis, o que, para Bordieu (2015), representa uma 
sobreposição de violência, capaz de contribuir e legitimar as desigualdades de gênero por vias simbólicas, uma vez que, segundo o mesmo autor, palavras fazem coisas, criam fantasias, medos, fobias ou mesmo representações falsas.

Conforme destaca Thompson (2001), a mídia passou a moldar o mundo em que hoje vivemos. Há poderes na política, na economia, na coerção, e também nas forças simbólicas. Esse último decorre da transmissão e recepção no qual os indivíduos estão sempre envolvidos na comunicação pela troca de conteúdos simbólicos - manipulação sobre os acontecimentos.

Ressalta-se que as notícias do webjornalismo, como meio de comunicação em massa, constituem-se numa dimensão simbólica inerente: "eles se relacionam com a produção, o armazenamento e a circulação de materiais que são significativos para os indivíduos que os produzem e os recebem" (THOMPSON, 2001, p. 19).

Deve-se atentar que as palavras ou expressões utilizadas pelas narrativas jornalísticas podem representar um mecanismo eficiente na produção e reprodução das desigualdades de gênero e podem funcionar como pedagogias culturais, pois, ao trazerem estereótipos em seu teor, reforçam os papéis tradicionais de gênero e, nesta via, educam os sujeitos (LOURO, 2018). Considera-se também que as notícias contribuem para a construção da própria realidade, e que a linguagem neutra não é possível (TRAQUINA, 2005).

Neste sentindo, "as palavras utilizadas permitem uma interpretação, e podem consolidar e reproduzir certos estereótipos, papéis e modelos, de comportamento e atitudes de gênero" (BANDEIRA; MAGALHÃES, 2019, p. 38).

\section{Aniquilamento simbólico}

A expressão "aniquilação simbólica" não é recente e foi, segundo Savietto (2015), utilizada inicialmente por Gerbner ainda no ano de 1972, para fazer alusão à ausência significativa das mulheres no mundo da ficção. Observa-se que, um pouco mais tarde, Tuchamn (1978) utilizou o termo "aniquilamento simbólico" para refletir a maneira limitada como as mulheres eram representadas na televisão, vez que exerciam papéis tradicionais de mãe e esposas e eram constantemente vítimas de estereotipia sexual.

Mais recentemente, Bandeira e Magalhães (2019) utilizaram a referida expressão em um estudo comparado sobre o feminicídio no Brasil e em Portugal, a partir do enquadramento e da análise de notícias sobre o tema. Para as autoras, a utilização da expressão "aniquilamento simbólico" tem o efeito de desqualificar mulheres como pessoas, associando-as a comportamentos e atitudes fora dos estereotípicos da feminilidade estabelecida pelos padrões vigentes.

Desse modo, a representação social pela condição do aniquilamento simbólico, retira da mulher a condição de sujeito de direitos, uma vez que 
ela é vista como uma descumpridora e transgressora de regras sociais, e, sob este prisma, essas mulheres passam a ser marginalizadas, ignoradas ou perseguidas por práticas sociais vigentes e reforçadas simbolicamente (BARRENO, apud BANDEIRA; MAGALHÃES, 2019).

De acordo com Freitas (2000), a ideia de que a natureza das mulheres as destina ao silêncio e à obscuridade está profundamente arraigada em nossas culturas, restritas ao espaço privado, fazendo com que as mulheres permaneçam invisibilizadas pelas democracias modernas, preconizadas por uma violência estrutural que assola nossas instituições.

Ainda, Bandeira e Magalhães (2019), ao mencionar Savietto (2015), ressaltam que os significados pelas representações negativas sobre o feminino acabam por moldar e definir padrões de comportamentos deturpados sobre as mulheres. A construção social das mulheres é produzida pelas práticas e representações simbólicas dentro de formações sociais dadas, ou seja, produzem os papéis e as prescrições sociais atribuídas às mulheres (LAMAS, 2000). Destaca-se ainda que o sociólogo Pierre Bourdieu (1989), em sua obra "O poder simbólico", aduz que a aniquilação simbólica é uma forma de violência sutil que ignora a legitimidade de uma identidade.

Pelo exposto, entendemos importante realizar a análise da violência de gênero contra mulheres venezuelanas a partir de representações sociais contidas em manchetes veiculadas no webjornalismo brasileiro. Isso porque acreditamos que, apesar dessas representações demonstrarem, em um primeiro momento, uma certa neutralidade sobre questões de gênero, elas podem acabar produzindo e reproduzindo o aniquilamento simbólico através de narrativas opressivas capazes de provocar a invisibilidade e a negação de mulheres como sujeito de direitos (BANDEIRA; MARTINS, 2019).

Consideramos, ainda, que o aniquilamento simbólico no caso específico se faz presente principalmente quando as migrantes venezuelanas são associadas pela mídia à prostituição, pobreza, fome, mendicância e outras vulnerabilidades sociais.

\section{Percurso metodológico}

Este é um estudo de análise qualitativa de conteúdo veiculado em manchetes publicadas em jornais digitais. Objetivou-se verificar a hipótese inicial de que a narrativa trazida nessas manchetes poderia, muitas vezes, constituir - de forma velada ou explícita - uma violência ou um estímulo desta contra as imigrantes venezuelanas que residem atualmente no Brasil, isso porque o ato de narrar é, antes de mais nada, um ato de produção de efeitos. A análise de conteúdo $(\mathrm{AC})$ é técnica metodológica que permite acessar con- 
teúdos manifestos (explícitos) e latentes (simbólicos) pelas manchetes catalogadas. Segundo Bardin (2009, p.15), "a análise do conteúdo é um conjunto de instrumentos de cunho metodológico em constante aperfeiçoamento, que se aplicam a discursos (conteúdos e continentes) extremamente diversificados".

Esclarece-se a opção pela análise das manchetes e não de todo o corpo das notícias por constituírem estas a primeira impressão que se adquire em relação à determinada veiculação. Inclusive, estudos recentes demostram que as manchetes são determinantes na percepção dos leitores em relação ao restante do conteúdo lido, afetando inclusive a maneira como os indivíduos vão se lembrar destas notícias (ECKER et al., 2014).

Assim, realizou-se, inicialmente, uma exploração em sítios de pesquisas online, utilizando-se os descritores migrantes/mulheres/venezuelanas, tendo este momento sido voltado para o reconhecimento da proposição e das narrativas veiculadas em três importantes jornais digitais (Folha de São Paulo, Estadão e VICE Brasil) no período de 2016 a 2019, assim como para a escolha das categorias, unidades de registro e critérios de inclusão de fatores a serem analisados, delimitados conforme a seguir:

Paralelamente, foi realizado um estudo bibliográfico e documental acerca das vulnerabilidades sociais presentes nos processos imigratórios contemporâneos, associando-as aos Direitos Humanos das mulheres, o que permitiu listar e selecionar dez manchetes de notícias relacionadas às imigrantes venezuelanas, como amostra. Destaca-se que as manchetes foram selecionadas com base nas narrativas veiculadas consideradas mais atentatórias, o que igualmente permitiu delimitar as categorias e unidades de registros acima expostas.

Quadro 1- Categorias, unidades de registro e critérios de inclusão.

\begin{tabular}{|l|l|l|}
\hline \multicolumn{1}{|c|}{ CATEGORIAS } & \multicolumn{1}{|c|}{ UNIDADES DE REGISTRO } & \multicolumn{1}{c|}{ CRITÉRIOS DE INCLUSÃO } \\
\hline $\begin{array}{l}\text { Depreciação da condição de } \\
\text { imigrante: XENOFOBIA }\end{array}$ & $\begin{array}{l}\text { Uso de expressões e palavras } \\
\text { que depreciaram o indivíduo por } \\
\text { sua condição de imigrante, de } \\
\text { estrangeiro. }\end{array}$ & $\begin{array}{l}\text { Quando o(a) autor(a) da } \\
\text { manchete - de forma explícita } \\
\text { ou implícita - depreciou o(a) } \\
\text { venezuelano(a) em razão da sua } \\
\text { condição de imigrante. }\end{array}$ \\
\hline $\begin{array}{l}\text { Desqualificação de imigrantes } \\
\text { venezuelanas em associação a } \\
\text { sexo e/ou à prostituição: VIO- } \\
\text { LÊNCIADE GÊNERO }\end{array}$ & $\begin{array}{l}\text { Uso de expressões e palavras } \\
\text { que desqualificaram o gênero } \\
\text { feminino das imigrantes venezu- } \\
\text { elanas. }\end{array}$ & $\begin{array}{l}\text { Quando o(a) autor(a) da man- } \\
\text { chete - de forma explícita ou } \\
\text { implícita - associou de forma } \\
\text { negativa as condições de mulher } \\
\text { e de imigrante. }\end{array}$ \\
\hline
\end{tabular}

Fonte: Autores

Paralelamente, foi realizado um estudo bibliográfico e documental acerca das vulnerabilidades sociais presentes nos processos imigratórios contem- 
porâneos, associando-as aos Direitos Humanos das mulheres, o que permitiu listar e selecionar dez manchetes de notícias relacionadas às imigrantes venezuelanas, como amostra. Destaca-se que as manchetes foram selecionadas com base nas narrativas veiculadas consideradas mais atentatórias, o que igualmente permitiu delimitar as categorias e unidades de registros acima expostas.

Em um último momento, foi realizada a análise de conteúdo das manchetes selecionadas, com o objetivo de se verificar a existência de narrativas que endossam discursos xenofóbicos e de violência de gênero e que, por consequência, acabaram provocando o aniquilamento simbólico das imigrantes venezuelanas pela mídia brasileira.

\section{Resultados}

Considerando a importância das manchetes das notícias na formação da opinião pública, não só por ser utilizada para atrair a atenção dos leitores como também por apresentar, sucintamente, o assunto abordado e por fornecer informações e predições a respeito das narrativas, realizamos a catalogação e análise de conteúdo (AC) das manchetes selecionadas, a saber:

Quadro 2a- Análises das Manchetes

\begin{tabular}{|l|l|l|}
\hline \multicolumn{1}{|c|}{ MANCHETE/TÍTULO } & \multicolumn{2}{c|}{ ANIQUILAMENTO SIMBÓLICO } \\
\cline { 2 - 3 } & \multicolumn{1}{|c|}{ XENOFOBIA } & \multicolumn{1}{c|}{ VIOLÊNCIA DE GÊNERO } \\
\hline $\begin{array}{l}\text { "Crise na Venezuela: o deses- } \\
\text { pero das que se prostituem na } \\
\text { fronteira com a Colômbia" }\end{array}$ & $\begin{array}{l}\text { Pobreza e da prostituição às } \\
\text { estrangeiras }\end{array}$ & $\begin{array}{l}\text { Desespero: fragilidade da mulher } \\
\text { da imigrante } \\
\text { Desqualificação da mulher } \\
\text { imigrante, prostituição como tra- } \\
\text { balho: fora dos padrões morais } \\
\text { da sociedade }\end{array}$ \\
\hline $\begin{array}{l}\text { "Venezuelanos sobrecarregam } \\
\text { serviços públicos em RR, que } \\
\text { vive crise fiscal. Hospitais lota- } \\
\text { dos e aumento da prostituição } \\
\text { e da violência são queixas dos } \\
\text { moradores de Boa Vista" 10 }\end{array}$ & $\begin{array}{l}\text { Responsabilização da s } \\
\text { obrecarga dos serviços públicos }\end{array}$ & $\begin{array}{l}\text { Associação da presença dos } \\
\text { venezuelanos com o aumento da } \\
\text { prostituição no município de Boa } \\
\text { Vista, em Roraima. } \\
\text { Desqualifica a mulher imigrante: } \\
\text { fora dos padrões morais da } \\
\text { sociedade }\end{array}$ \\
\hline
\end{tabular}

Fonte: Jornal Vice (2018), Jornal Estadão (2019), Jornal Folha de São Paulo (2016 a 2019) e autores

9 Manchete extraída do Jornal Folha de São Paulo. Data da publicação: 28 abr. 2019. Autora: Karenina Velandia. Disponível em: https://www1.folha.uol.com.br/mundo/2019/04/crise-na-venezuela-o-desespero-dos-que-se-prostituem-na-fronteira-com-a-colombia.shtml. Acesso em: 5 mai. 2020.

10 Manchete extraída do Jornal Folha de São Paulo: - Data da publicação: 26 agosto 2018. Disponível em: https:// www1.folha.uol.com.br/mundo/2018/08/venezuelanos-sobrecarregam-servicos-publicos-em-rr-que-vive-crise-fiscal.shtm. Acesso em: 4 abr. 2020. 
Quadro 2b- Análises das Manchetes

\begin{tabular}{|l|l|l|}
\hline \multicolumn{1}{|c|}{ MANCHETE/TÍTULO } & \multicolumn{2}{|c|}{ ANIQUILAMENTO SIMBÓLICO } \\
\cline { 2 - 3 } & \multicolumn{1}{|c|}{ XENOFOBIA } & \multicolumn{1}{c|}{ VIOLÊNCIA DE GÊNERO } \\
\hline $\begin{array}{l}\text { "As venezuelanas que decidi- } \\
\text { ram se prostituir na Colômbia } \\
\text { por causa da crise"11 }\end{array}$ & $\begin{array}{l}\text { Associação das imigrantes } \\
\text { venezuelanas à prostituição e a } \\
\text { pobreza }\end{array}$ & $\begin{array}{l}\text { As venezuelanas estariam } \\
\text { "optando" pela prostituição } \\
\text { mesmo tendo a opção de outros } \\
\text { trabalhos "honestos" (trabalhos } \\
\text { formais) } \\
\text { Desqualificação das mulheres } \\
\text { imigrantes }\end{array}$ \\
\hline $\begin{array}{l}\text { "Com crise, prostitutas venezu- } \\
\text { elanas disputam clientes na } \\
\text { Colômbia"12 }\end{array}$ & $\begin{array}{l}\text { Associação das imigrantes ven- } \\
\text { ezuelanas à prostituição }\end{array}$ & $\begin{array}{l}\text { Acredita-se haver certa ironia na } \\
\text { utilização das palavras "disputam" } \\
\text { e "clientes", como se as mulheres } \\
\text { venezuelanas estivessem em } \\
\text { uma batalha em prol da prosti- } \\
\text { tuição, como se desejassem esta } \\
\text { situação. }\end{array}$ \\
\hline $\begin{array}{l}\text { "Prostituição de venezuelanas } \\
\text { avança com a imigração em } \\
\text { massa do norte"13 }\end{array}$ & $\begin{array}{l}\text { Aumento da prostituição com a } \\
\text { imigração venezuelana }\end{array}$ & $\begin{array}{l}\text { Reforçando estereótipos da des- } \\
\text { qualificação da mulher imigrante } \\
\text { condicionada a prostituição }\end{array}$ \\
\hline $\begin{array}{l}\text { "Prostituição de índias venezu- } \\
\text { elanas gera temor no extremo } \\
\text { norte do Brasil"14 }\end{array}$ & $\begin{array}{l}\text { Houve a afirmação de que } \\
\text { as índias venezuelanas estão } \\
\text { provocando temor no extremo } \\
\text { norte do Brasil }\end{array}$ & $\begin{array}{l}\text { Recurso apelativo dos estereóti- } \\
\text { pos de gênero e raça, para } \\
\text { anunciar a notícia } \\
\text { Houve associação explícita das } \\
\text { índias venezuelanas à prostituição }\end{array}$ \\
\hline $\begin{array}{l}\text { "Migração de venezuelanas } \\
\text { aumenta tráfico de mulheres na } \\
\text { fronteira com o Brasil"15 }\end{array}$ & $\begin{array}{l}\text { Aumento de tráfico de mulheres } \\
\text { com a imigração venezuelana }\end{array}$ & $\begin{array}{l}\text { Desqualificação da mulher } \\
\text { imigrante } \\
\text { Culpabiliza a mulher imigrante }\end{array}$ \\
\hline
\end{tabular}

11 Manchete extraída do Jornal Folha de São Paulo- Data da publicação: 13 jan. 2017. Redação da BBC Brasil.Disponível em: https://www1.folha.uol.com.br/paywall/login.shtml?https://wwwl.folha.uol.com.br/mundo/2017/01/ 1849593-as-venezuelanas-que-decidiram-se-prostituir-na-colombia-por-causa-da-crise.shtml. Acesso em: 5 jun. 2020.

12 Manchete extraída do Jornal Folha de São Paulo. Data da publicação: 17 set. 2017. Autora: Sylvia Colombo. Disponível em: https:/wwwl.folha.uol.com.br/paywall/login.shtml?https:/wwwl.folha.uol.com.br/mundo/2017/09/ 1919199-com-crise-prostitutas-venezuelanas-disputam-clientes-na-colombia.shtml. Acesso em: 20 mar. 2020.

13 Manchete extraída do Jornal Folha de São Paulo/ Data da publicação: 13 jan. 2017 - Autores: Marcelo Toledo e Danilo Verpa. Disponível em: https://www1.folha.uol.com.br/cotidiano/2017/04/1879719-prostituicao-de-venezuelanas-avanca-com-imigracao-em-massa-no-norte.shtml. Acesso em: 05 jan. 2020.

14 Manchete extraída do Jornal Folha de São Paulo. Data da publicação: 25 nov. 2016. Autor: Marcelo Toledo. Disponível em: https://brasil.blogfolha.uol.com.br/2016/11/25/3165/. Acesso em: 5 jan. 2020.

15 Manchete extraída do Jornal Estadão. Data da publicação: 11 jul. 2019 Autora: Cyneida Correa. Disponível em: https://internacional.estadao.com.br/noticias/geral,migracao-de-venezuelanas-aumenta-trafico-de-mulheres-na-fronteira-com-o-brasil,70002917089. Acesso em: 5 jan. 2020. 
Quadro 2c- Análises das Manchetes

\begin{tabular}{|l|l|l|}
\hline \multicolumn{1}{|c|}{ MANCHETE/TÍTULO } & \multicolumn{2}{c|}{ ANIQUILAMENTO SIMBÓLICO } \\
\cline { 2 - 3 } & \multicolumn{1}{|c|}{ XENOFOBIA } & \multicolumn{1}{c|}{ VIOLÊNCIA DE GÊNERO } \\
\hline $\begin{array}{l}\text { "Prostituição vira opção para } \\
\text { imigrantes venezuelanas em } \\
\text { Roraima"16 }\end{array}$ & $\begin{array}{l}\text { Prostituição com a imigração } \\
\text { venezuelana }\end{array}$ & $\begin{array}{l}\text { Desqualificação da mulher imi- } \\
\text { grante associada à sua opção de } \\
\text { trabalho como prostituta }\end{array}$ \\
\hline $\begin{array}{l}\text { "Tráfico de venezuelanas es- } \\
\text { timula prostituição em Trindad } \\
\text { e Tobago" 17 }\end{array}$ & $\begin{array}{l}\text { Houve associação do aumento } \\
\text { de tráfico de mulheres com a } \\
\text { imigração venezuelana }\end{array}$ & $\begin{array}{l}\text { Justifica e culpabiliza as } \\
\text { mulheres imigrantes de forma } \\
\text { explícita do tráfico de mulheres } \\
\text { com a migração de venezuelanas }\end{array}$ \\
\hline $\begin{array}{l}\text { "Uma noite com "lasochenta", } \\
\text { as venezuelanas que se pros- } \\
\text { tituem em Boa Vista" 18 }\end{array}$ & $\begin{array}{l}\text { Prostituição com a imigração } \\
\text { venezuelana }\end{array}$ & $\begin{array}{l}\text { Além da associação das venezu- } \\
\text { elanas à prostituição, houve a } \\
\text { utilização da expressão "las- } \\
\text { ochenta" para se referir ao valor } \\
\text { cobrado pelas venezuelanas } \\
\text { que se prostituem em BoaVista. } \\
\text { Inferiu-se, portanto, que, além } \\
\text { de se prostituir, as venezuelanas } \\
\text { estariam se sujeitando a receber } \\
\text { pouco pela prostituição, como se } \\
\text { fossem "baratas". }\end{array}$ \\
\hline
\end{tabular}

Fonte: Jornal Vice (2018), Jornal Estadão (2019), Jornal Folha de São Paulo (2016 a 2019) e autores

\section{Considerações finais}

Constatou-se, pela amostragem analisada, que, além das discriminações relacionadas à condição de não-nacionais, as imigrantes venezuelanas vêm sendo não raramente representadas de forma a fomentar a desigualdade de gênero através do webjornalismo brasileiro. Isso porque, ao analisar o conteúdo de cada uma das dez manchetes, verificou-se que, em todas, havia o uso de palavras, de expressões, determos ou de associações capazes de depreciar as imigrantes venezuelanas não somente pela condição de estrangeiras, mas também em razão do gênero feminino, constituindo o aniquilamento simbólico na representação destas mulheres.

16 Manchete extraída do Jornal Estadão. Data da publicação: 11 jul. 2019 Autora: Cyneida Correa. Disponível em: https://internacional.estadao.com.br/noticias/geral,migracao-de-venezuelanas-aumenta-trafico-de-mulheres-na-fronteira-com-o-brasil,70002917089. Acesso em: 5 jan. 2020.

17 Manchete extraída do Jornal Estadão. Data da publicação: 11 jul. 2019 Autora: Cyneida Correia. Disponível em: https://acervo.estadao.com.br/pagina/\#!/20190711-45922-nac-12-int-a12-not/busca/venezuelanas+prostitui\%C3\%A7\%C3\%A3o. Acesso em: 5 jan. 2020.

18 Manchete extraída do Jornal Vice. Data da publicação: 28 ago. 2018 Autora: Débora Lopes. Disponível em: https:// www.vice.com/pt_br/article/paw9mv/las-ochenta-as-venezuelanas-que-se-prostituem-em-boa-vista. Acesso em: 4 fev. 2020. 
Assim, foi possível inferir da análise das manchetes que os jornais digitais vêm frequentemente descrevendo a migração venezuelana como um problema, mas em conotação negativa, sem o cuidado de descrição do contexto de forma mais clara e abrangente da questão a ser noticiada, e representando as imigrantes venezuelanas como pessoas à margem do suposto contexto social normal, associando-as exclusivamente à pobreza, à marginalização, à criminalização e, principalmente, à prostituição, de forma a fomentar a manutenção das desigualdades sociais de gênero e da xenofobia, ferindo o princípio da isonomia, da dignidade da pessoa humana e dos fundamentos dos Direitos Humanos, uma vez não se perceber nas manchetes analisadas uma abordagem que remeta à obrigação moral de ajudar, ao acolhimento e à hospitalidade como posicionamento humanitário adotado pelo país, e sim tendo todas cunho eminentemente de mensagem depreciativa.

\section{Referências}

ACNUR. Agências da ONU reforçam a atenção a meninas e mulheres migrantes refugiadas no Brasil. 25 jan. 2019. Disponível em: https://www.acnur.org/ portugues/2019/01/25/agencias-da-onu-reforcam-atencao-a-meninas-emulheres-migrantes-e-refugiadas-no-brasil/. Acesso em: 5 fev. 2020.

BANDEIRA, Lourdes Maria; MAGALHÃES, Maria José. A transversalidade dos crimes de femicídio/feminicídio no Brasil e em Portugal. Revista da Defensoria Pública do Distrito Federal, Brasília, v.1, n.1, p. 29/56, 2019.

BANDEIRA, L. M. Violência, gênero e poder: múltiplas faces. In: Stevens, Cristina et al. (org.). Mulheres e violências: interseccionalidades. Brasília, DF: Technopolitik, 2017. p. 136 - 223.

BARDIN, Laurence. Análise de conteúdo. Lisboa: Edições 70/LDA,2009.

BÓGUS, Lucia Maria M.; FABIANO, Maria Lucia Alves. O Brasil como destino das migrações internacionais recentes: novas relações, possibilidades e desafios. Ponto-e-Vírgula: Revista de Ciências Sociais, São Paulo, n. 18, p. 126145, 2015.

BOURDIEU, P. A dominação masculina: a condição feminina e a violência simbólica. 1. ed. Rio de Janeiro: Bestbolso, 2014. 
BOURDIEU, P. A dominação masculina. 5. ed. Rio de Janeiro: Bertrand Brasil, 2019.

BOURDIEU, P. Economia das trocas linguísticas. São Paulo: EDUSP, 2008.

BRASIL. Governo do. Operação acolhida: histórico. Disponível em: https:// www.gov.br/acolhida/historico/. Acesso em: 3 jul. 2020.

BRASIL. Governo do. Lei. 13.445, de 24 de maio de 2017. Institui a Lei de Migração. Disponível em: http://www.planalto.gov.br/ccivil_03/_ato20152018/2017/lei/l13445.htm. Acesso em: 13 mar. 2020.

BRASIL. Governo do. Câmara dos Deputados. $1^{\circ}$ Relatório da comissão externa sobre a crise na fronteira com a Venezuela. Disponível em: https://www.camara.leg.br/proposicoesWeb/prop_ mostrarintegra?codteor $=1774525$ \&filename $=R E L+1 / 2019+C E X V E N E Z$. Acesso em: 24 mar. 2020.

CHAUÍ , M. Ética, política e violência. In: CAMACHO, T. (Ed.). Ensaios sobre violência. Vitória: Edufes, 2003. p. 39-59.

DINIZ, G. R. S. ; ANGELIM, F. P. Violência doméstica - porque é tão difícil lidar com ela? Revista de Psicologia da Unesp, Assis-SP, 2(1), p. 20-35, 2003.

ECKER, U. K., Lewandowsky, S., CHANG, E. P.; PILLAI, R. The effects of subtle misinformation innewsheadlines. Journal of experimental psychology: applied, Washington, 20(4), p. 323- 335, 2014.

LAMAS, M. Diferencias de sexo, género y diferencia sexual. Nueva Época, México, v. 7, n. 8, p. 7-10, 2000/2001. Disponível em: https://www.redalyc. org/pdf/351/35101807.pdf. Acesso em: 5 jan. 2020.

LOURO, G. L.; NECKEL, J. F.; GOELLNER, V. S. Corpo, Gênero e Sexualidade: um debate contemporâneo na educação. Petrópolis, RJ: Vozes, 2018.

MACHADO, L. Z. Perspectivas em confronto: relações de gênero ou patriarcado contemporâneo? Série Antropologia, Brasília, 284, p. 2-19, 2000.

SAFFIOTI, H. I. B. Já se mete a colher em briga de marido e mulher. São Paulo em Perspectiva - Revista da Fundação Seade, São Paulo, 13(4), p. 82-91, 1999. 
SCOTT, Joan. Gênero: uma categoria útil para análise histórica. Recife: S.O.S. Corpo, 1995.

THOMPSON, John. A mídia e a modernidade: uma teoria social da mídia. Tradução: Wagner de Oliveira Brandão. 12. ed. Petrópolis, RJ: Vozes, 2001.

VENTURA, Miriam. Imigração, saúde global e direitos humanos. Cad. Saúde Pública, Rio de Janeiro, 34(4) p. 1-2 2018. Disponível em: http://www.scielo. $\mathrm{br} / \mathrm{pdf} / \mathrm{csp} / \mathrm{v} 34 \mathrm{n} 4 / 1678-4464-\mathrm{csp}-34-04-e 00054118 . p d f$. Acesso em: 10 jan. 2020.

WIHTOL DE WENDEN, Catherine. La question migratoire au XXI siècle. 2nd éd. Revue et augmentée. Paris: Le Presses de Sciences Po, 2013.

Recebido em: 17 de novembro de 2020. Aprovado em: 5 de maio de 2021. 